\title{
Development of a data acquisition system for an oceanographic buoy
}

\author{
M. Pérez Chavarría*1 ${ }^{1}$ E. Estudillo Zamora ${ }^{2}$ \\ ${ }^{1}$ Instituto de Investigaciones Oceanológicas, Universidad Autónoma de Baja California \\ Carretera Ens-Tij, km 105. tel (646) 17446 01, Ensenada B.C., México \\ *email; mperez@uabc.mx \\ ${ }^{2}$ Centro de Bachillerato Tecnológico Industrial y de Servicios No. 41 \\ Carretera Transpeninsular, km 15. Ensenada B.C., México. C.P. 22800
}

\section{ABSTRACT}

This work presents the development of a data acquisition system for an oceanographic buoy that includes the necessary sensors to measure the meteorological and marine variables which are involved in the physical processes in the ocean-atmosphere interface. In general, the development consists of three phases:

- $\quad$ Either digital or analogical conditioning of the signals resulting from the different sensors.

- Development of the instrument's control system.

- Development of both control and instrument-user communication programming. Among the most important characteristics of the system are the following:

- The buoy has sensors to measure wind direction and speed, atmospheric pressure, relative humidity, air temperature, water temperature, marine current direction and speed, and wave height.

- The system is programmable, this is, the sampling intervals can be programmed as well as the start and end dates of an experiment by means of a personal computer and a user-friendly software in the Windows platform.

- $\quad$ The instrument was designed for a low consumption of energy and with a system of solar cells to recharge the battery. To date, partial results have been generated in respect to the measurement of the oceanographic variables because the physical structure of the buoy has not been finished yet. It is important to point out that the development of this instrument is pioneer in the field of oceanographic electronic instrumentation in our country, besides it helps in the formation of qualified human resources.

Keywords: buoy, data acquisition, oceanographic instrumentation.

\section{RESUMEN}

El presente trabajo consiste en el desarrollo de un sistema de adquisición de datos para una boya oceanográfica (IIO system) que incluye los sensores necesarios para medir las variables meteorológicas y marinas, que se involucran en los procesos físicos en la interfase océano-atmósfera. El desarrollo consiste en forma general, de tres etapas:

- Acondicionamiento, ya sea digital o analógico de las señales de los diferentes sensores.

- Desarrollo del sistema de control del instrumento.

- Desarrollo de la programación tanto de control como de comunicación instrumento-usuario.

Entre las características más importantes del sistema se tienen las siguientes:

- La boya cuenta con sensores para medir dirección y rapidez del viento, presión atmosférica, humedad relativa, temperatura del aire, temperatura del agua, dirección y rapidez de las corrientes marinas y amplitud del oleaje.

- El sistema es programable, es decir, se pueden programar los intervalos de muestreo así como las fechas de inicio y fin de un experimento mediante una computadora personal y un programa amigable en la plataforma Windows.

- El instrumento se diseñó para tener bajo consumo de energía y con un sistema de celdas solares para recargar las baterías.

A la fecha se han obtenido resultados parciales con respecto a la medición de las variables oceanográficas pues aún no se ha concluido la estructura física de la boya. Es importante señalar que el desarrollo de este instrumento es pionero dentro del campo de la instrumentación electrónica oceanográfica en nuestro país, además de coadyuvar a la formación de recursos humanos de calidad.

Palabras clave: Boya, adquisición de datos, instrumentación oceanográfica. 


\section{Introduction}

In the municipality of Ensenda B.C. there is a great number of regional problems that arise from natural phenomena, which obviously are not controllable. However, such problems could be prevented if there were serious studies whose results permitted the proposal of actions intending to generate predictions, and in this way, minimization of the noxious effects of such phenomena when taking adequate precautions. Among others, the large droughts that impact the agricultural sector from San Quintín B. C. and the wine growing area of Guadalupe Valley can be mentioned which, in addition, cause large forest fires in the whole region. If prediction of such drought seasons was possible, at least approximately, what and how much to grow could be predetermined and decisions in respect to forest fires could be made. Another big problem is erosion in the coastal zone, which strongly damages human settlements that have been developed there. If wave studies were available, reliable and non-reliable zones could also be predetermined. This kind of studies would only be possible if a data bank composed by time series of several years of the oceanographic variables registered in the area was available. For this reason, the Electronic Instrumentation Laboratory (EIL) of the Universidad Autónoma de Baja California (UABC) worked at developing the prototype of an oceanographic buoy in order to generate a data bank with time series of the main meteorological and marine variables. The organization of the present work is as follows; in section 2, the sensors of the variables to be measured are described. In section 3, a block diagram of the instrument is shown and a brief description of its operation is given. The programming is described in section 4 , in section 5 , the results are shown and in section 6 , the conclusions are described.

\section{Sensors}

In order to measure the wind speed, an ultrasonic sensor [2] is used, with operation intervals from 0 to $60 \mathrm{~m} / \mathrm{s}$ and precision of \pm 0.1 for the speed, and for the direction, the interval goes from 0 to $355^{\circ}$ with precision of $\pm 2^{\circ}$. The room temperature is measured by a thermistor [4] in an interval of -50 to $50^{\circ} \mathrm{C}$, with precision of $\pm 0.1^{\circ} \mathrm{C}$. The pressure sensor [5] operation principle is capacitive and its measurement interval goes from 50 to $1300 \mathrm{hPa}$, with precision of $\pm 0.10 \mathrm{hPa}$. The water temperature is registered using a thermistor [7], in an interval from -10 to $43^{\circ} \mathrm{C}$ and precision of $\pm 0.5^{\circ} \mathrm{C}$. The wave height is estimated by an accelerometer [9], in an interval from 0 to $10 \mathrm{~m}$ and precision of $\pm 10 \%$. In respect to relative humidity, the sensor is capacitive [4] in an interval from 0 to $100 \%$ humidity and precision of $\pm 3 \%$. The marine current speed and direction are measured by a Doppler effect sensor [7], the speed in an interval from 0 to $500 \mathrm{~cm} / \mathrm{s}$ with precision of \pm 2 $\mathrm{cm} / \mathrm{s}$ and the direction interval is from 0 to $360^{\circ}$ with precision of $\pm 5^{\circ}$. The reference in respect to the magnetic north is calculated with an electromagnetic compass [6], with precision of $\pm 2^{\circ}$. All the sensors used by the system were already calibrated by their manufacturer, that is the reason why the calibration equipment is not required.

\section{3. system's description}

The buoy (IIO system) is a field data acquisition system based on a micro controller [10] which supervises and executes the instrument's main tasks such as the data acquisition by the sensors, information backup, data transmission and sampling interval synchronization by means of a real time watch. The block diagram of the instrument is shown in Figure 1. The instrument's main components are the sensors, the signals conditioning, the analogical/digital conversion, the micro controller, the feeding sources and the telemetry. 


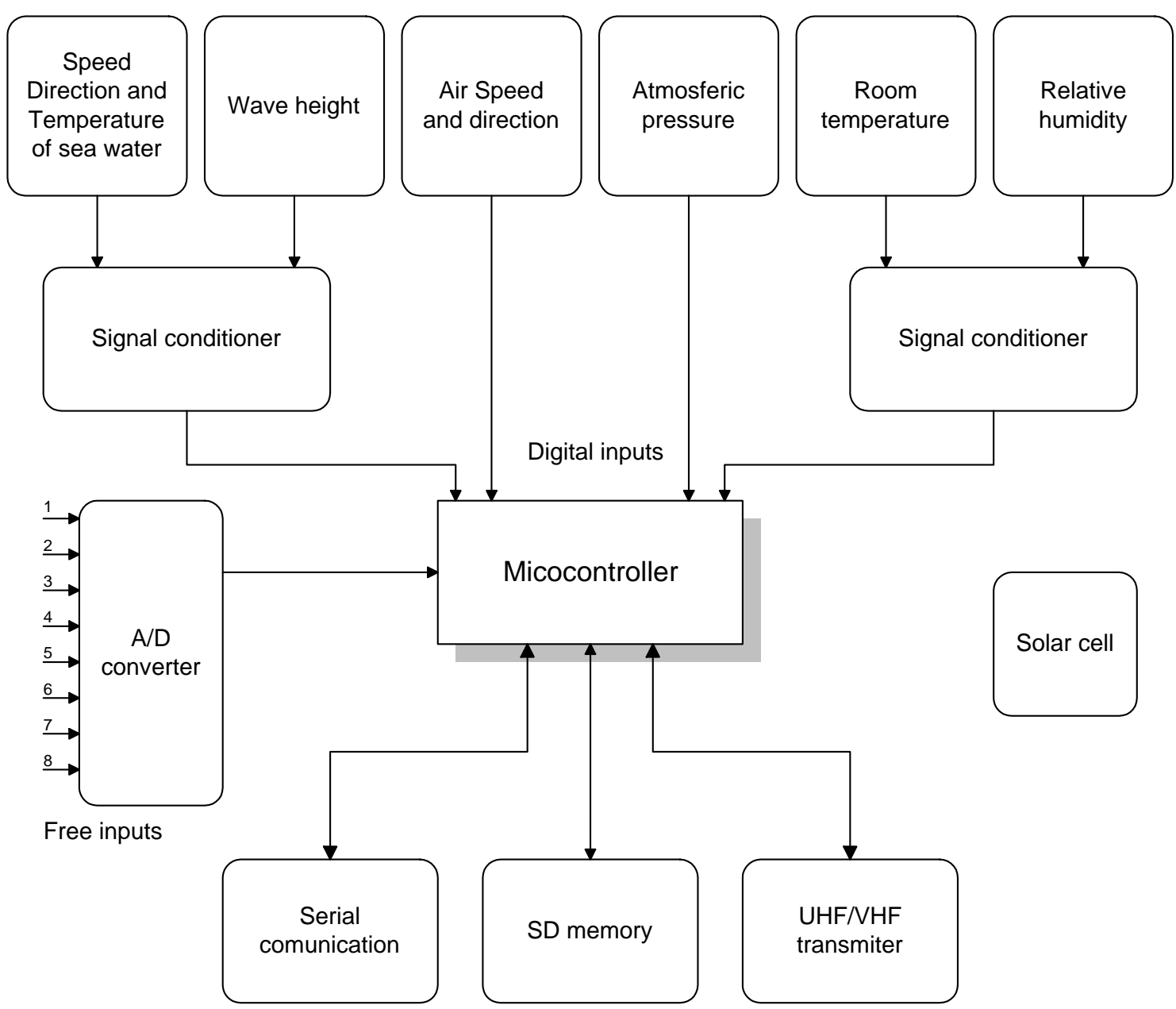

Figure 1. General block diagram of the instrument. This figure shows the main components and the measurable variables used and retrieved by the data acquisition system.

As can be observed from the diagram, all signals coming from the sensors are digital and they are connected to different terminals of the microcontroller which avoids the need for a multiplexer system. The data acquisition system also has an analog to digital converter with eight inputs in order to be used if another geophysics variable needs to be measured.

In general, the instrument's operation is as follows: the variable data acquisition is carried out in time intervals programmed by the user, which can be from a minute up to a day. When the time interval set by the user is completed, the micro controller first applies the control signal to the voltage regulators to feed the needed circuits by means of which it indicates that a new burst of measurements will start. After this, the micro controller starts reading all the sensors; the ones supplied with digital output $[3,8]$ are directly read, and for the ones with analogical output, a converter is used to carry out the reading. Simultaneously to the sensors reading, the buoy is transmitting (UHF/VHF) and backing up the data in the memory. Once the measurements and parameter updating were done, the control signal for the voltage regulators is turned off and the micro controller is set to low consumption mode 
until the next time an interval to start a new cycle is completed. In case the data transmission fails, the data will be saved to a SD FLASH memory [11]. Each variable is read and stored in 2 bytes. In the measurement of each time interval, 22 bytes will be used. According to these calculations, the storage of the data during a set period of time will be guaranteed because it will take 44 years to fill up the SD flash memory if data is retrieved in a sampling time interval per minute. All the data stored in the memory might be accessed by the serial port of a personal computer with the help of a software specially designed for that purpose. In order to ensure that what is transmitted is received correctly, the captured information by the sensors is codified in the INTEL HEX format for its transmission and storage in the memory.

The buoy can be operated in two different modes. In the monitor mode, the instrument operation can be tested, visualizing the data acquired by the sensors through a monitor, either by connecting the instrument to a PC through a serial port or by telemetry, this is in order to verify that values captured by the sensors fall within the adequate parameters as well as to check that the reading/writing of the memory is correct. In this mode, it is also possible to program the system or recover the information saved in memory. The field mode is the typical buoy's operation state since, before taking it to the field, it is programmed with the experiment's start and end dates and the variables sampling intervals, and it is set to stand-by until it is waken up by a real time watch in order to carry out its tasks autonomously.

\section{Programming}

The programming consists of two main pieces of software: the control software, in Assembly language for Motorola micro controller 08 [11], carries out tasks such as sampling acquisition, data back-up in memory and the instrument's general temporization. This program is totally transparent to the user. The user communication software (Figure 2), in Visual Basic V6 language, allows us to program the instrument with the start and end dates of a given experiment as well as the variables sampling intervals, update the real time watch and access the data saved in the memory so they can be backed-up in a personal computer disk. It also allows checking the adequate operation of the transducers when the instrument is set to the monitor mode in the self-test option and, in addition, it controls the data transmission/reception by telemetry.

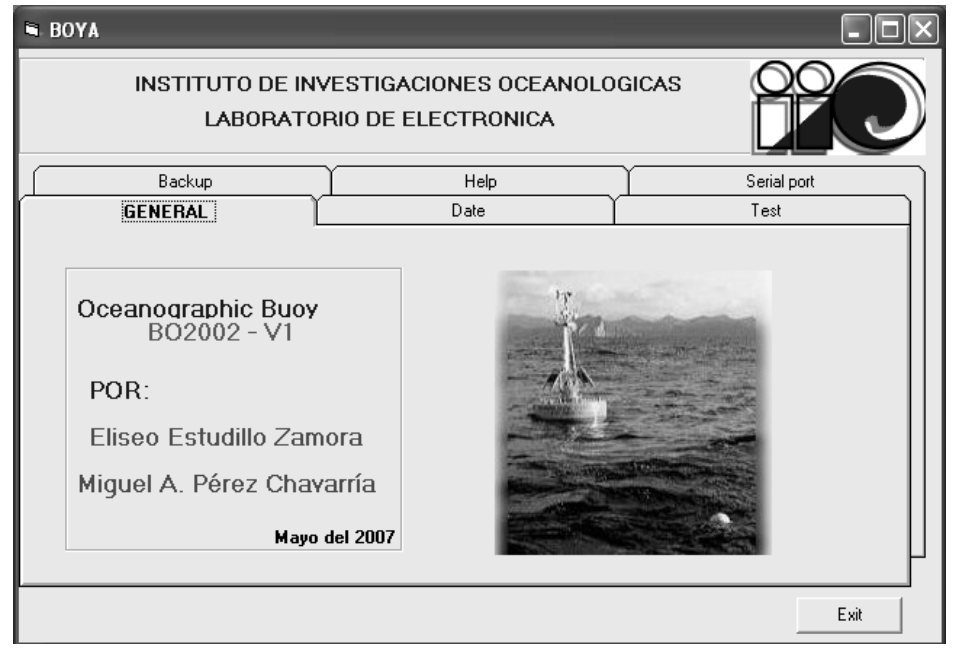

Figure 2. Main screen of the user-communication program. 


\section{Results}

It is necessary to make clear that two main parts, the control electronics and the physical structure, constitute the complete buoy system. The physical structure consists of a floating system inside of whose inner part the acquisition circuits and the feeding sources are adapted, and a mast/post is fixed in the external upper part where the sensors which will measure the meteorological variables and the data transmission antenna are incorporated. In the lower part of the floating system, the sensors for measuring the marine variables are fixed. The physical structure has not been finished yet, which is why it has not been possible to carry out field tests. However, laboratory tests were made for each of the sensors separately, considering the calibration sheet supplied by the manufacturers for each one of them. Finally, once the electronic system was complete, all the sensors were set up next to an Aanderaa and a Young meteorological stations, and the instrument was programmed so that it acquired all the variables for 20 days, storing the time series in a personal computer in order to, later on, have them compared from the Aanderaa and Young stations $\{1\}$. In general, the signals are not the same, which was expected because the temporizations are different since Aanderaa delivers a value averaged in the sampling time interval and the Young and IIO systems delivers an instantaneous value. Figures 3 and 4 show the comparison between the wind speed and direction signals for the three meteorological stations, as can be observed, for the wind speed (Figure 3), all of them have the same behavior, but $I I O$ and Young systems have a better correlation coefficient (Riio_y $=0,99$ ) than IIO and Aanderaa systems (Riio_a $=0,80$ ). For the wind direction (Figure 4), once again, we found a good correlation coefficient between the $\mathrm{IIO}$ and Young systems (Riio_y $=0.88$ ) but a worse one for the IIO and Aandeaa systems (Riio_a $=0.29$ ). These variations are mainly due to the difference in temporizations and because the sensors are not located at the same height.

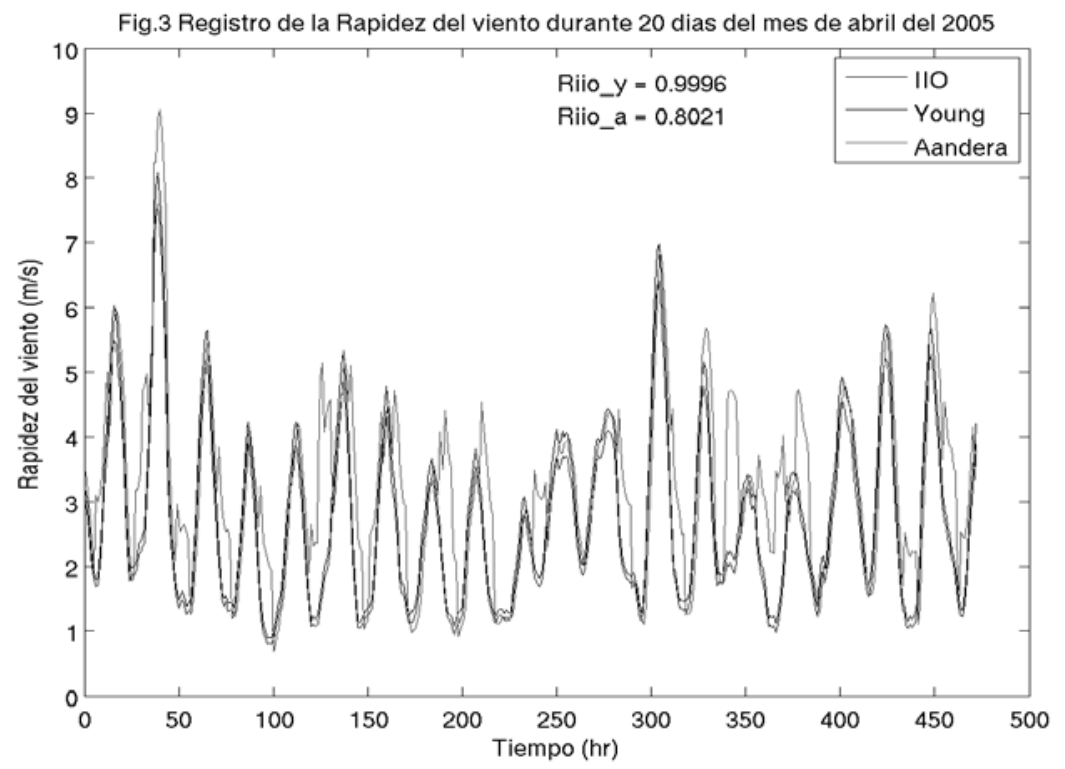

Figure 3. Comparison between the wind speed signals of the 3 meteorological stations, IIO_system (black line), Young_system (blue line) and Aanderaa_system (red line). 


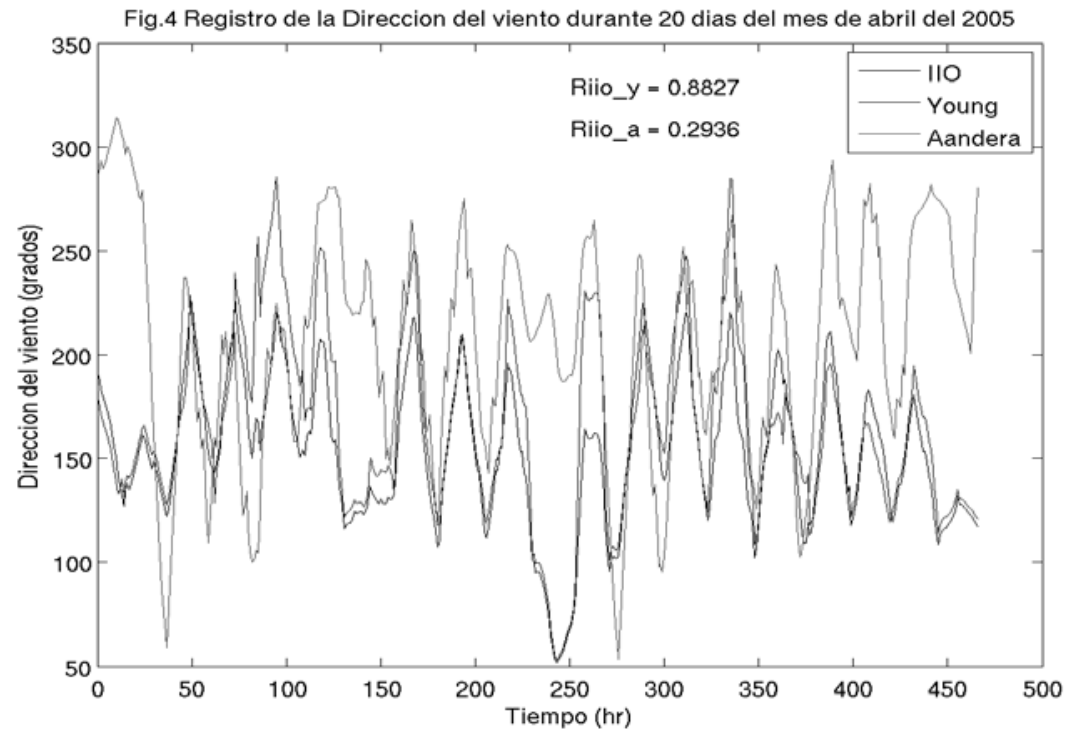

Figure 4. Comparison between the wind direction signals of the 3 meteorological stations, IIO_system (black line), Young_system (blue line) and Aanderaa_system (red line).

The comparison between the room temperature signals from IIO and Aanderaa systems is shown in Figure 5.

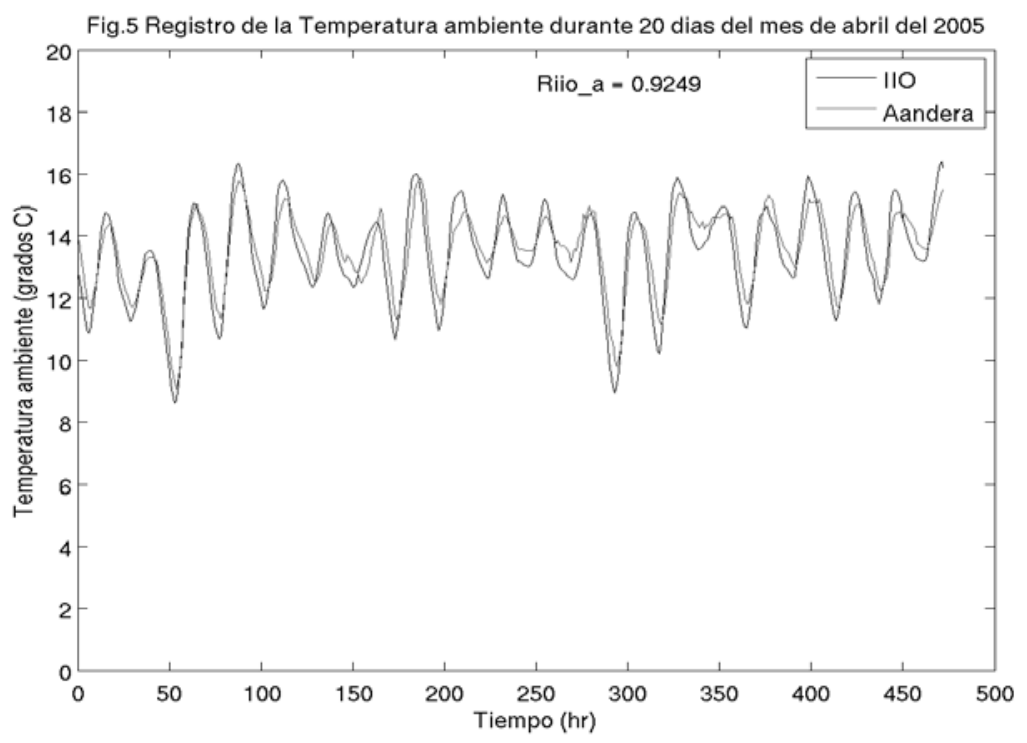

Figure 5. Comparison between room temperature signals. The red line corresponds to Aanderaa station and the black line to the IIO system. 
It can be observed that the buoy's system overestimates the temperature value, it is believed that this is mainly because the IIO sensor does not have a radiation protector. However, the IIO temperature signal follows the Aanderaa signal with a good correlation coefficient (Riio_a $=0,92$ ). In respect to the atmospheric pressure (Figure 6), the signals comparison is shown in Figure 6. It can be observed that both instruments' behavior is the same with a very good correlation coefficient (Riio_a $=0,99$ ).

The relative humidity signals are compared in Figure 7. Once again, a difference is observed due to the radiation protector absence, but we find a good correlation coefficient (Riio_a $=0,98$ ).

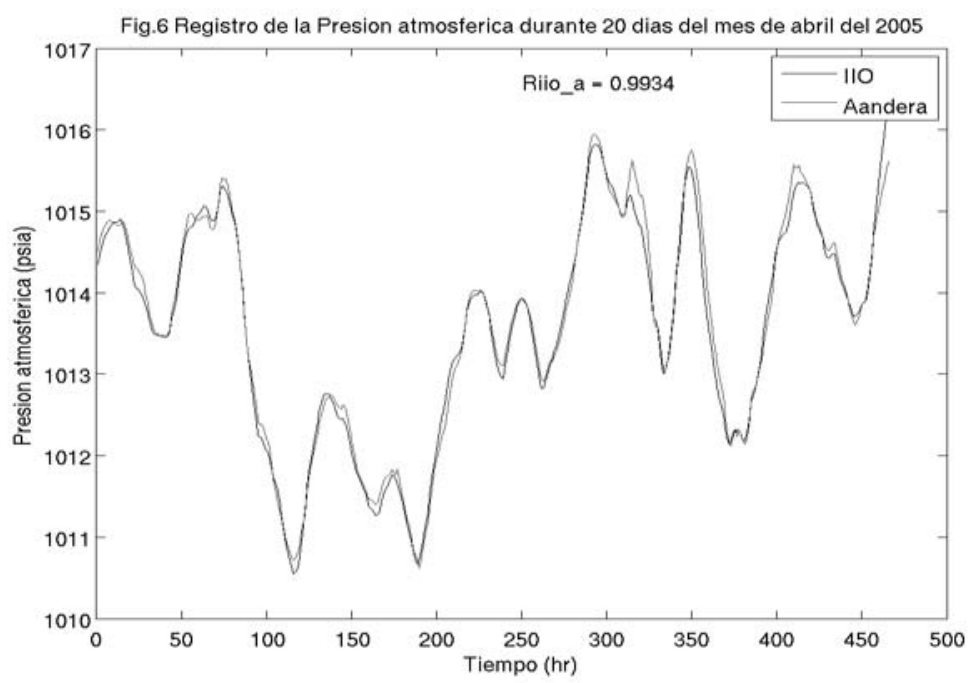

Figure 6. Comparison between atmospheric pressure signals. The red line corresponds to Aanderaa station and the black line to the IIO system.

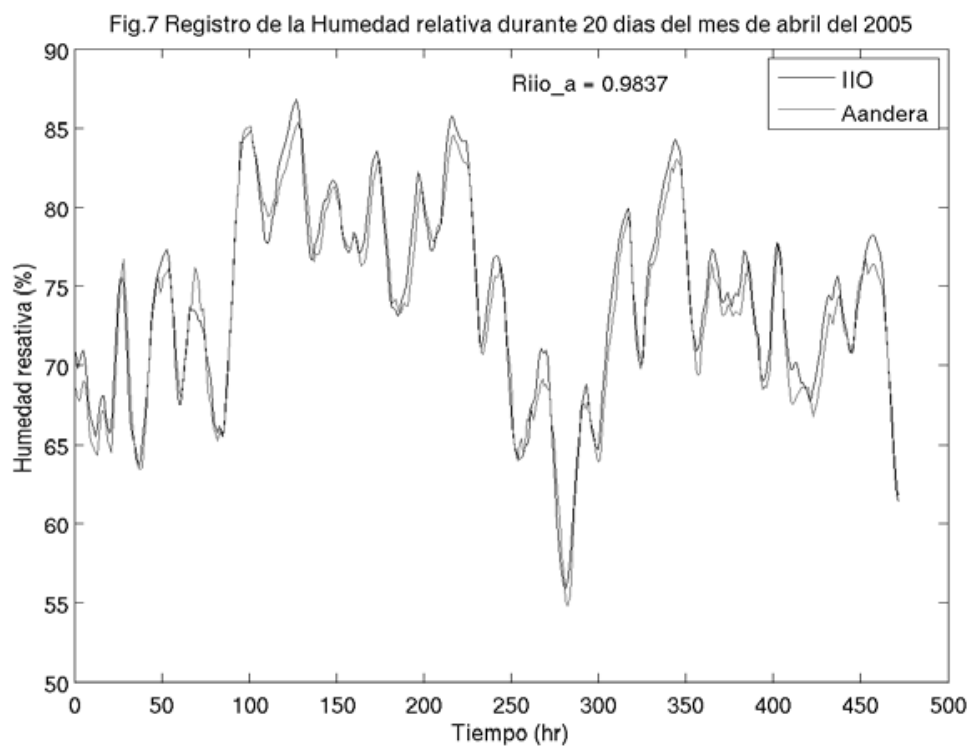

Figure 7. Comparison between relative humidity signals. The red line corresponds to Aanderaa station and the black line to the IIO system. 


\section{Development of a data acquisition system for an oceanographic buoy, M. Pérez Chavarría et, al, 193-201}

\section{Conclusions}

A data acquisition system for the measurement and retrieval in real time of the meteorological and marine variables was developed with satisfactory results. In summary, the meteorological variables are wind direction and speed, atmospheric pressure, relative humidity and air temperature whilst marine variables are water temperature, marine current direction and speed, and wave height.

It is observed from the figures above that, in general, the IIO system signals follow the same behavior as the signals from the meteorological stations Young and Aanderaa, with a very good correlation coefficients between them, which indicates that the acquisition system developed works correctly. In conclusion, the expectations for this project were met due to the fact that the data acquisition system was fully developed and the physical structure of the oceanographic of the buoy system has been designed and built up to its $60 \%$ structural development.

\section{References}

[1] Aanderaa instrument. 1999. " Operating manual CMB3280". pp 32

[2] Handar A TSI Company. 1998. "Model 425 series of ultrasonic wind sensor". pp76

[3] SDI-12 Support Group. 2000. "A serial-digital interface standard for microprocessor based sensor ", pp 30

[4] Met One instruments. 1999. "Relative humidity/temperature sensor model 083D", pp 15

[5] Vaisala. 1999. "PTB210 series digital barometers with serial output". pp 26
[6] R.M. Young company. 2000. "Model 32500 electronic compass". pp 7

[7] Aanderaa instrument. 2000. "Doppler current sensor 3900". pp 4

[8] Aanderaa instrument. 2000." Signal Types - The VR22 and SR10 Signal Formats".

\{http://www.aanderaa.com/VR22andSR10.htm\}25 de febrero, 2003

[9] Aanderaa instrument. 2000. "Wave height sensor 3595". pp 4

[10] Motorola. 1998. "''MC68HC908GP32 HCMOS Microcontroller unit". pp 404

[11] Atmel. 2001. "DataFlash AT45DB321B". \{http://eu.atmel.com/atmel/acrobat/doc2223.pdf\}25 de febrero, 2003

\section{Acknowledgments}

This work was supported by SIMAC-CONACyT, Mexico under ref. 4076-344.

English translation by Verónica Rangel Aguirre and Julieta Nunez Oviedo. 


\section{Authors Biography}

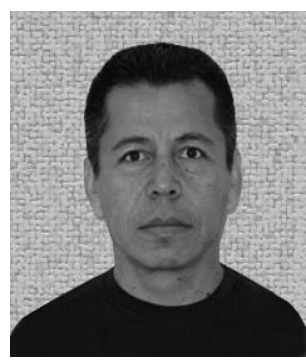

\section{Miguel Angel PÉREZ-CHAVARRÍA}

He received his B.S. degree in physics from the Faculty of Mathematical Physics of the Universidad Autónoma de Nuevo León, Monterrey N.L., Mexico. Dr. Pérez also holds an M.S. degree in electronic instrumentation and an M.S. degree in physical oceanography from the CICESE, Ensenada B.C., Mexico as well as a Ph.D. degree in teledetection and statistical methods from L'Université Pierre e Marie Curie, París, Francia. His research interest lies in neural network application to geophysical data analysis. Currently, he is a full-time B-level researcher in the area of physical oceanography at the Institute for Oceanographic Research of the Universidad Autónoma de Baja California.

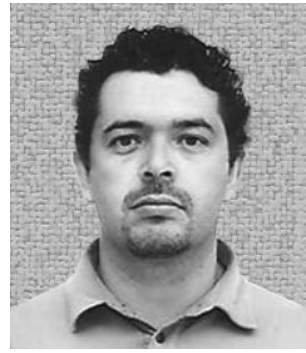

\section{Eliseo ESTUDILLO-ZAMORA}

He received his B.S. degree in electronics from the Faculty of Engineering of the Universidad Autónoma de Baja California, Ensenada B.C., Mexico. He has an M.S. degree in engineering from the same university. His research interest lies in development and teaching in the area of electronic instrumentation. Currently, he is the local president of the Research and Technological Development Academy of Centro de Bachillerato Tecnológico Industrial y de Servicios No. 41. 